\title{
Enlightenments from Meissen Porcelain to Ni Xing Pottery Brand
}

\author{
Shao Qiang Ning1,Jun Na Wang2 \\ ${ }^{1}$ Guangxi Normal University School of Design, Guilin, Guangxi, China, \\ 723924855@qq.com, \\ ${ }^{2}$ Guangxi Polytechnic of Construction, Nanning, Guangxi, China,
}

\begin{abstract}
Meis-sen Porcelain, as the world-top ceramic brand and the number one brand in Germany which is praised as "the mother of European china", is strongly influenced by Chinese porcelain.Depending on imitation and development, creative designing, strict management and up-todate sale, it has created glorious history and culture, rank-ing the most famous porcelain brand worldwide. Nixing pottery today to change the present situation of the product without brand should learn from meisen porcelain brand setting up experience, set up their own brands.
\end{abstract}

Keywords: Meissen Porcelain, Ni Xing Pottery, Brand, Comparison, Enlightenment

\section{The relationship between Meissen Porcelain and Ni Xing Pottery}

characteristics were spotless,mildness and brightness, led the European courts to abandon the heavy golden and silve wares. Using Chinese porcelain became a trend as well as a symbol of wealth profit made European people desperate about the secret of porcelain production.In the sixteenth century, Italy produced " Meissen porcelain", in the seventeenth century, France produced "glazed porcelain". In
According to the Qin County Annauls: the Qinzhou pottery was invented before Tang Dynasty and became more delicate in Tang.Because of the change of wars and governments, the production of Qinzhou pottery kept a balance in producing and selling. By the end of Qing Dynasty and the beginning of Republican period, opium came to China and Ni Xing pottery developed for producing smoking pipies.Except for pipes, it also produced teapots, stationary and goods for appreciation. The products sold to more than half of China and countries in Southeast Asia though Vietnam.In 1915, Ni Xing Pottery went abroad for the first time to participate in the World Exhibition in Panama, San Francisco ,U.S. And won the gold prize. ( Fig. 1) It was called the "Four most famous pottery" in China together 
with Zisha Pottery in Yixing, Rongchang Pottery in Sichuan and Jianshui Pottery in Yunnan.Ni Xing Pottery appeared 1000 years earlier than Meissen Pottery, but the Meissen Pottery influenced by Chinese pottery, especially Yixing Pottery,are known worldwide.Meanwhile, Qinzhou Ni Xing Pottery are seldom known currently in the porcelain field, even in native Guangxi province.Compared to Meissen Porcelain, we can gain the enlightenment that it is necessary for the emploees of Ni Xing Pottery to build the brand and raise the influnce of $\mathrm{Ni} \mathrm{Xing}$ pottery.

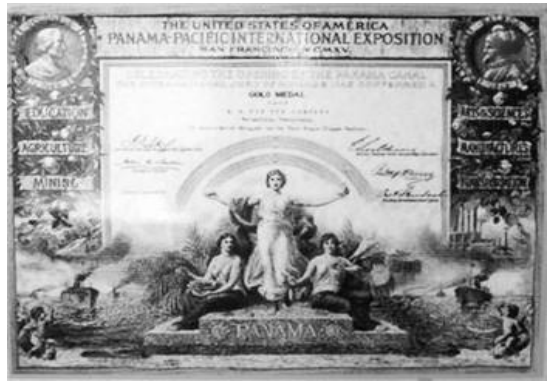

Fig. 1: nixing pottery" in 1915Panama Pacific International Exposition" gold medal award certificate

\section{Enlightenment from raw material and production technology}

\subsection{Production of raw materials}

\subsubsection{Comparison between the exploit and usage of raw material}

The material of Meissen Porcelain was a mixture of china clay,bassanite, and quartz which was produced in Saxony,Germany.People began to exploit clay mineral as early as 1974.By now the year production of white clay is around 300 tons, which is also one of the olddest stillexploiting mineral up to now.Ni Xing
Pottery uses the raw material Zini Pottery produced in Qinzhou, which comes from the red soil on the banks of Qin river.Mixed with the hard clay on the west bank and the soft one on the east bank, it came into shape after cleaning and choosing.According to statistics, the clay source total production of Qinzhou Ni Xing Pottery reaches 1500 to 1700 million cubic meters. The exploit is basically in the air,but the development standard is low and is still expansive and scattered form of exploit.There still remains damaging the biosystem and excessive exploit.

\subsubsection{Enlightenment}

The exploit of the raw material of Meissen Porcelain followed the plan at the very start, which protect and use the unrenewable clay source effectively.Due to that,the products' number and quality of Meissen Porcelain are guaranteed.There still remains damaging the biosystem and excessive exploit in th production procedures of $\mathrm{Ni}$ Xing Pottery.Even if the source is rich and abundant,we need to learn using the clay source from Meissen Porcelain .First, we should find the distribution and the amount of the clay source;second,the partition and plan for the clay source exploit should be made; then, we should made the management norms of the clay source.

\subsection{Production Technology}

\subsubsection{The comparison in production technology.}

In Meissen porcelain 300 years of history, it has always maintained a handmade craft, Even in industrialized development today,In addition to using the power from firing, Other production processes still retains The initial stage that build a plantearly construction of the handmade production process. It 's every piece of porcelain products,Even porcelain goods every ornament,Are all hand made ( Fig. 2 ) . Because it is handmade, 
the longer production cycle, Even an ordinary cup, its set of production amounted to more than 100 days. Some more complex shape product even up to half a year of the production cycle.As early as in 1764 , Meissen porcelain factory attaches great importance to the artistic quality of product, In the world of China history of the earliest established his own art school, At the same time it also is the Grand Duchy of Isaacson School of art. Meissen porcelain every painting, modelling division must be approved by the school for three years to ten years of professional training. To be a Meissen porcelain a porcelain link excellent technicians need more long time. The sketch course as a basic course in the technicians are learning three years half time has been to learn, they also learn human anatomy and repeat the exercise depicting autumn leaves, birds, flowers and other patterns;But nixing pottery development so far, its production has been most for semi automated production mode, but in the decoration is still maintained the traditional handmade. The mode of production is mostly made of semi automatic process, so the nixing pottery production cycle takes roughly thirty days.Employees are mostly local idle labor force, their artistic accomplishment of the overall low, professional school practitioners scanty.

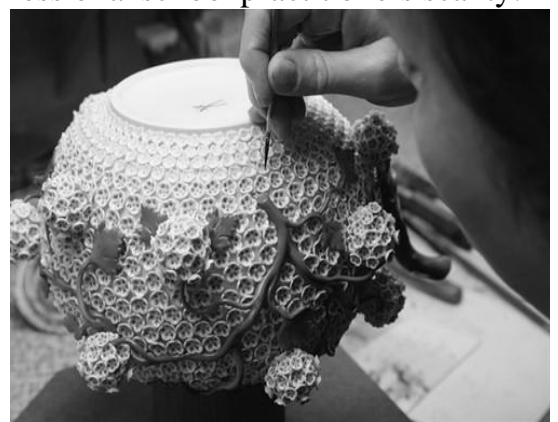

Fig. 2 handmade porcelain decoration

\subsubsection{Enlightenment}

Meissen porcelain development so far has been in use pure handmade craft production and meticulous division of labor, production cycle is relatively longer. Engaged in the production of pre-service through complete and scientific professional training, have good professional accomplishment. But nixing pottery in the production process has been mostly half automation, production division of labor is rough, practitioners of professional quality whole is poorer. After contrasting the following enlightenments. First, the establishment of professional ceramic art academy, training employees in the professional accomplishment. Second, product grading production, highend products all use of handmade crafts. In third, the production steps detailed division of labor, production cycle lengthened.

\section{The enlightenment in styles and fea- tures and market running}

\subsection{Styles and features}

\subsubsection{The comparison in styles and fea- tures.}

Since the beginning of Meissen porcelain production for royal service, therefore the product has always been a royal aristocratic luxury style.Because of its production at the beginning of imitation of Chinese ceramic based, early porcelain decorative motifs are marked with colors of China, the Chinese myths and legends, bird fish fruit are the original copy imitation. After continuous improvement, in 1739designed with Baroque style underglaze red dragon and "blue onion pattern". In" blue onion pattern" for shaping of the material produced by the product ( Figure 3) has been the classic collectibles. This style until today is still widely respected by the world of porcelain industry. In addition, Meissen porcelain decorative col- 
orful gorgeous, the color formula has thousands of, and has a strict secret protection measures, this is also a unique point of Meissen porcelain. Ni Xing Pottery went through the late Qing Dynasty when the scholars and the formation of the classical style.; Since the nineteen eighties economic and cultural development of today's multicultural style. In addition, Qinzhou nixing pottery does not add any ceramic glaze case, because of the clay contains rich in ferric oxide composition, firing temperature reaches 1200 degrees Celsius, to produce color change namely" Kiln". This variable Texture needed polished surface oxides can fully show though not glaze and delicate texture, smooth, colorful colorful characteristics.

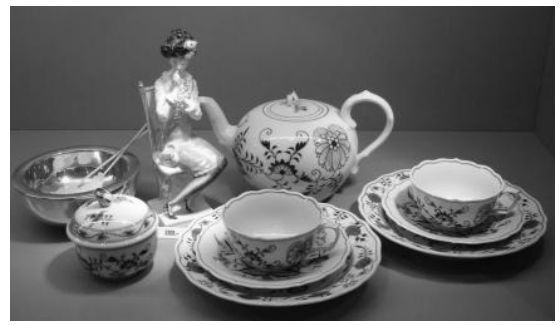

Fig 3 " blue onion pattern" porcelain

\subsubsection{Enlightenment}

Meissen porcelain aristocratic luxury style, classical Chinese style has always existed in his three years of development history. Ni Xing Pottery 's style at the time of the social environment changes, did not carry out its development history style. Ni Xing Pottery in the future development process in response to its artistic style finishing, on the basis of upgrading and transformation, to design such as Meissen porcelain" blue onion pattern" as the classic style of the products. And the use of its unique" Kiln " features, as the development of new products mainly point.

\subsection{Market running}

\subsubsection{The comparison in market run- ning.}

Meissen porcelain since the production of its ownership belongs to the state, until after the unification of Germany, Meissen porcelain to self-financing joint-stock company. Meissen has always been adhering to the replication and innovation coexist route, in order to meet the special needs of customers, porcelain is also provided with a model and decorative pattern of Archives.So it still can produce a hundred or three hundred years ago products. In addition, Meissen porcelain in either design or marketing in more than 300years always adhere to the international strategy. Nowadays, Meissen porcelain are $75 \%$ exported to foreign countries. Not only that, porcelain also opens up another production direction, namely the production of interior decoration the desired tile or decorative porcelain paintings. Berlin's most upscale hotel Adelung is one of its clients. By now, Qinzhou Ni Xing pottery has developed a wide range of products. Production is the main type of domestic pottery and art ceramic. Daily ceramic main varieties of tea, coffee, purple rice cookers, electric boiler, steamer, soup pots, pots, pots and so on. Art pottery vases, smoked tripod, process art ceramics, antique pottery characteristics of ceramic treasures, tourism souvenirs etc.. In addition, some have a master of the craft enterprises also accept custom. Nowadays the nixing pottery exported to the domestic 28 provinces, city, autonomous regions, and exported to Japan, the United States, Germany, Britain, France, Belgium, more than 30 countries and regions of Hong Kong and Macao. In more than 20 enterprises in export only one, but the export products to most plant pots and daily pottery. The company is mostly in the domestic sales, the main sales in Guang xi Zhuang own area. 


\subsubsection{Enlightenment}

From the Meissen porcelain and nixing pottery market comparison we get the following enlightenment: Firstly, increase the government's support to cultivate leading enterprises; Secondly, exploit new market, establish a diversified marketing mode; Thirdly, take advantage of ASEAN economic circle, develop products which are suitable for ASEAN to increase export.

\section{The Enlightenment in brand pro- motion and influence}

\subsection{Brand promotion}

\subsubsection{The comparison in brand promo- tion}

Meissen porcelain dating back more than300 years of history, in this more than 300 years of Meissen porcelain experienced war and social system change Never stop production. As early as in nineteenth Century has been in theworld exposition is often the award it also often be elected country gift for the German government leaders visit when world leaders to foreign. Wheresoever the country or region is, there is a Meissen porcelain agency at the most poshest business street. Meissen porcelain as it has complete mold, pattern color formulation Library, Using these rich resources now with the production studio,and set up a exhibition hall including production products, tourists visit, works display(Figure4). Because of the exhibition hall and the presence of Meissen town beautiful scenery attracts nearly three hundred thousand visitors. This not only stimulate the local economy in the form of Meissen porcelain made very good promotion and publicity function. As early as 1915 , the nixing pottery attend the "Panama Pacific International Exposition" win the gold medal. In 1930 to participate in the World Ceramic Exposition won gold medal. So far in 1949to participate in the international and domestic exhibitions and won won the of all kinds of more than 40 awards. In 1997 by the State Council included in the focus of the protection of traditional arts and crafts. Especially in 2006, China Arts and Crafts Master Li Renping's" high drum flowers bottles" ( Figure 5) awarded the United Nations educational, scientific and cultural organization "world outstanding handicrafts emblem" . In 2010 to become the Shanghai World Expo licensed merchandise. In addition, in recent decades, nixing pottery mainly used as gifts for guests by many departments and institutions of Guangxi Zhuang Autonomous Region in all kinds of celebration activities

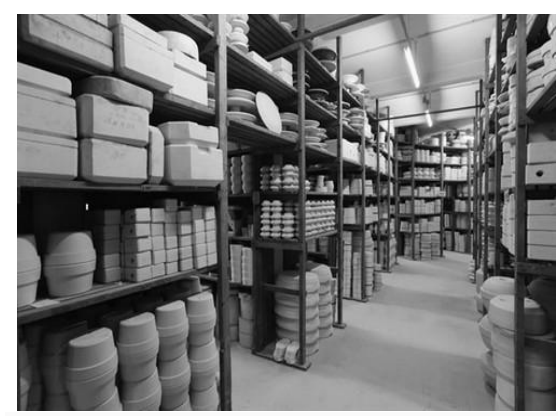

Fig 4 Meisen porcelain mould save the library

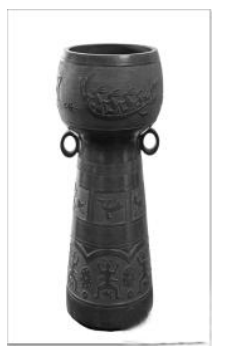

Fig 5 high drum flower vase

\subsubsection{Enlightenment}

Compared with Meissen Porcelain in the brand promotion,we gain the enlightenment that: first,franchise stores should be set in the high-terminal district of large cities across the country.Second, we can invite celebrities to shoot a cultural trailer 
in order to increase propagandist strength.Third,we should build up a history exhibition museum of the Ni Xing Pottery history to produce the porcelain,welcome the visitors and put the works on show.

\subsection{Brand influence.}

\subsubsection{The influence of brand compari- son.}

Mention Meissen porcelain, people's minds will appear a variety of praise,It is taste, money, status, rights" pronoun". This has a history of over 300 years of German porcelain brand, after the German Porsche second high-grade goods. With its elegant design, the royal temperament, pure handmade is well known in the world. In today's Germany, Meissen porcelain still represents the society, people have to Meissen porcelain and proud. Even in the elite wedding bride, dowry goods if Meissen porcelain tableware on behalf of the bride's family 's social status. Since reforming and opening, nixing pottery ushered in another development peak. According to statistics, production of Qinzhou nixing pottery enterprises existing size of the factory more than 20 , about more than 3000employees. The main production daily ceramics and art ceramic two categories is given priority to, and have a small amount of building ceramic production. But in this a lot of production scale, people or very few know nixing pottery for what they are, some people even take it with Yixing Zisha confusion. But nixing pottery product price is relatively low, even the arts and crafts masters is far lower than the price other similar products and prices.

\subsubsection{Enlightenment}

The comparison with Meissen Porcelain gives us enlightenment that: firstly,we should design the brand symbol that can truly stand for the history and background of Ni Xing Pottery.Secondly, we must put emphasis on the quality and develop products of high class. Then, we need to create new industry chain and make development strategies.

\section{Conclusion}

Ni Xing Pottery has a history of more than 1300 years, whose unique geographic characteristics are special raw material and "kiln" and granding and polishing process.In the economics booming days,Ni Xing Pottery gain new opportunities. We can draw the conclusion that the power of products cannot be ignored from the successful case of Meissen Porcelain . Nowadays, the employees in Ni Xing Pottery should follow the trend of localization on basement of the formers' creation, and to express geographic culture thoroughl. Meanwhile,they should build up brands belonging to themselves in mixed with the essence of the traditional culture and modern fashion cultural beauty concept.I am convinced that there is going to be a wonderful Chinese porcelain brand in the world of porcelain brands,Ni Xing Pottery in Qinzhou!

\section{Acknowledgement}

[1]The project of Guangxi center of humanities and social sciences:"Guangxi art and design research team of characteristic industries", contract NO.TD2011011

[2]Project by Guangxi Province Office of Education: "Research on forms of folk tourism products in Guangxi ",contract NO.201106LX053

\section{Reference}

[1] W.Q. Mao, China Ceramic industry, Vol. 1994 No.5, p.58.

[2] W.Q. Mao, Ceramic history, Vol. 2007 No.1, p.34-36.

[3] D.Lu,Z.B.Wu, Art and design ( Theory ), Vol. 2008 No.10, p.195-197.

[4] N.Wang,S.Xiao, Foshan ceramics, Vol. 2008 No.2, p.6-8. 
[5] W.Ma, Zhejiang arts and crafts, Vol.1997 No.3, p.38-40.

[6] J.T.Huang, Famous brand, Vol.2011 No.2, p.15-17.

[7] L.Lin, Collection· auction, Vol.2011 No.8, p.20-23. 